\title{
Pharmacologic Properties of Proton Pump Inhibitors
}

\author{
Lynda S. Welage, Pharm.D., FCCP \\ Since their introduction into clinical practice in the 1980s, proton pump \\ inhibitors (PPIs) have proved to be of enormous value in the management of \\ acid peptic disorders. They have become the treatment of choice for most, if \\ not all, acid-related gastrointestinal disorders, including gastroesophageal \\ reflux disease, peptic ulcer, and Zollinger-Ellison syndrome. With approval of \\ an intravenous formulation, the benefits of PPIs are extended to critically ill \\ patients for whom oral drug administration is often unsuitable. Five PPIs are \\ approved for clinical use in the United States. Although they share a common \\ core structure and mechanism of action, it is important to understand the \\ general pharmacology of these agents and how they differ from histamine $2_{2}$ \\ receptor antagonists in order to optimize PPI therapy. \\ (Pharmacotherapy 2003;23(10 Pt 2):74S-80S)
}

\section{OUTLINE}

Overview of Acid Secretion

Chemistry and Mechanism of Action of Proton Pump Inhibitors

Pharmacokinetics

Pharmacodynamics

Potential for Drug Interactions

Summary

Proton pump inhibitors (PPIs) are potent, highly selective inhibitors of the $\mathrm{H}^{+}, \mathrm{K}^{+}$-adenosine triphosphatase (ATPase) enzyme, which catalyzes the final step in gastric acid secretion. Because they are more effective than histamine ${ }_{2}$-receptor antagonists $\left(\mathrm{H}_{2} \mathrm{RAs}\right)$, they have largely supplanted $\mathrm{H}_{2} \mathrm{RAs}$ for treatment of acid-related diseases, particularly persistent or severe disease. ${ }^{1}$ The PPIs available as oral formulations in the United States are pantoprazole, omeprazole, esomeprazole, lansoprazole, and rabeprazole. With the availability of the first intravenous PPI, pantoprazole, the drugs' benefits now can be extended to patients who require acid suppression but are unable to take intact capsules or tablets. ${ }^{2}$ Potential indications for intravenous PPIs include acid-related conditions, such as gastroesophageal

From the Department of Clinical Sciences, University of Michigan College of Pharmacy, Ann Arbor, Michigan.

Address reprint requests to Lynda S. Welage, Pharm.D., College of Pharmacy, University of Michigan, 428 Church Street, Ann Arbor, MI 48109; e-mail: lswelage@umich.edu. reflux disease, in patients who are unable to take oral agents, and hypersecretory states, such as Zollinger-Ellison syndrome. They also can be administered to prevent acid aspiration syndrome during induction of surgical anesthesia, stressrelated mucosal bleeding, and peptic ulcer rebleeding. ${ }^{3-5}$

Clinicians must understand not only how PPIs differ from $\mathrm{H}_{2} \mathrm{RAs}$, but how individual PPIs differ. Most important, they must be able to identify indications for both oral and intravenous therapy. Knowledge of their pharmacologic characteristics can aid in correct drug selection and optimization of therapy.

\section{Overview of Acid Secretion}

Gastric acid secretion occurs in response to neurocrine, paracrine, and endocrine stimuli. ${ }^{5-7}$ Specifically, receptors located on the basolateral membrane of the parietal cell respond to acetylcholine, histamine, and gastrin stimulation (Figure 1). ${ }^{8}$ Gastrin can stimulate acid secretion directly; however, more important, it is a potent activator of enterochromaffin-like (ECL) cells to release histamine, which activates the histamine receptor located on the basolateral surface of the parietal cell. ${ }^{6,7}$

Activation of basolateral receptors leads to intracellular release of secondary messengers that activate protein kinases. ${ }^{9}$ The final step in the 
Table 1. Pharmacokinetic Parameters of Proton Pump Inhibitors with Implications for Clinical Efficacy and Safety Profile

\begin{tabular}{|c|c|c|c|c|c|}
\hline Parameter & $\begin{array}{c}\text { Pantoprazole } \\
40 \mathrm{mg}\end{array}$ & $\begin{array}{c}\text { Lansoprazole } \\
30 \mathrm{mg}\end{array}$ & $\begin{array}{c}\text { Omeprazole } \\
20 \mathrm{mg}\end{array}$ & $\begin{array}{c}\text { Esomeprazole } \\
40 \mathrm{mg}\end{array}$ & $\begin{array}{c}\text { Rabeprazole } \\
20 \mathrm{mg}\end{array}$ \\
\hline $\mathrm{pK}_{\mathrm{a}}^{13}$ & 3.96 & 4.01 & 4.13 & 4.13 & 4.9 \\
\hline $\begin{array}{l}\mathrm{AUC}_{0-\infty}(\mu \mathrm{mol} \bullet \mathrm{hr} / \mathrm{L})^{16} \\
\text { Day } 1(\text { range }) \\
\text { Day } 5\end{array}$ & $9.9-15.9^{15,16}$ & $5.0-5.2^{15,16}$ & $\begin{array}{c}1.1-2.0^{15,16} \\
2.23^{15}\end{array}$ & $\begin{array}{c}4.3-7.3^{16,17} \\
11.21^{17}\end{array}$ & $2.2^{16}$ \\
\hline Absolute bioavailability (\%) & $77^{1}$ & $80-85^{1}$ & $\begin{array}{l}30-40 \text { initially, } \\
65 \text { after } \\
\text { repeated } \\
\text { dosing }\end{array}$ & $\begin{array}{l}64 \text { initially, } \\
89 \text { after } \\
\text { repeated } \\
\text { dosing }\end{array}$ & $52^{1}$ \\
\hline Serum elimination half-life (hrs) & $1.0-1.9^{1}$ & $1.3-1.7^{1}$ & $0.5-1.0^{1}$ & $1.2^{17}$ & $1.0-2.0^{1}$ \\
\hline
\end{tabular}

$\mathrm{AUC}_{0-\infty}=$ area under the concentration-time curve from zero to infinity.

secretion of gastric acid is activation of the parietal cell $\mathrm{H}^{+}, \mathrm{K}^{+}$-ATPase enzyme, commonly referred to as the proton pump. ${ }^{6,7,9}$ When acid secretion is stimulated, the parietal cell undergoes dramatic morphologic transformation, and the $\mathrm{H}^{+}, \mathrm{K}^{+}$-ATPase enzyme and potassium and chloride symporters are transported from tubulovesicles and fuse with the secretory canaliculus. $^{6,7}$ The proton pump exchanges intracellular hydrogen ions for luminal potassium ions on a one-to-one basis to maintain intracellular electroneutrality and pumps hydrogen ions into the lumen. Thus, stimulation of $\mathrm{H}^{+}, \mathrm{K}^{+}$-ATPase enzymes is the final common pathway for acid secretion. Whereas $\mathrm{H}_{2} \mathrm{RAs}$ block one of the first steps in acid secretion-the histamine receptor located on the basolateral membrane of the parietal cell-PPIs block the final common pathway.

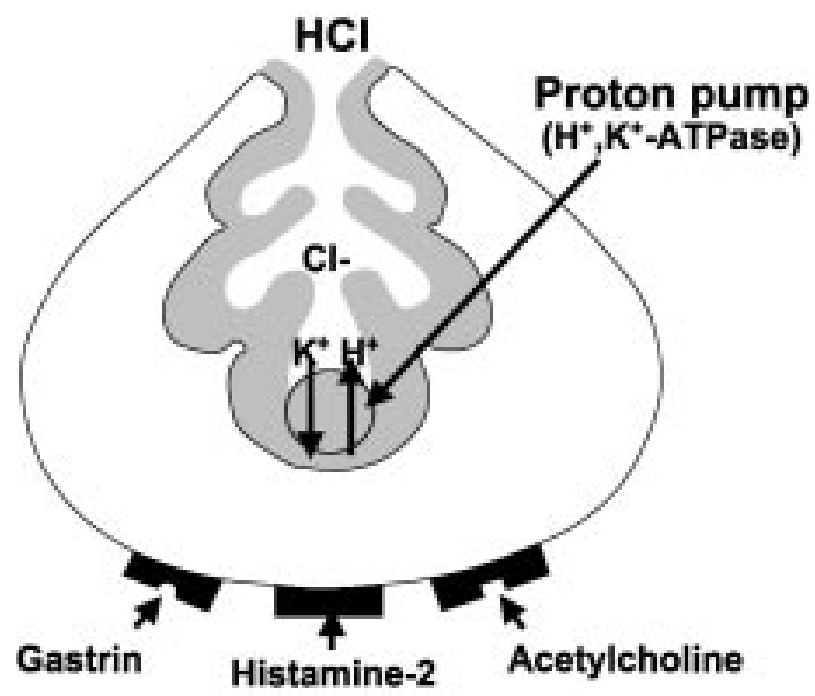

Figure 1. Site of action of proton pump inhibitors. (Adapted from reference 8 with permission.)

\section{Chemistry and Mechanism of Action of Proton Pump Inhibitors}

The PPIs share a common core structure and mechanism of action: they are substituted benzimidazoles that bind covalently to the $\mathrm{H}^{+}, \mathrm{K}^{+}$ATPase enzyme in parietal cells and thereby inhibit acid secretion. They are asymmetric in structure, which leads to formation of two identical, but nonsuperimposable, mirrorimage molecules (isomers or enantiomers). ${ }^{10}$ Omeprazole, lansoprazole, pantoprazole, and rabeprazole are marketed as racemic mixtures containing equal amounts of $\mathrm{R}$ - and Senantiomers. ${ }^{10}$ Esomeprazole, which contains only the S-enantiomer of omeprazole, is also approved for use in the United States. ${ }^{11}$

All PPIs are prodrugs and require acid to become protonated and converted to the active form. ${ }^{12}$ Omeprazole, lansoprazole, and esomeprazole are available as enteric-coated delayed-release pellets and pantoprazole and rabeprazole as tablets to protect the compounds from premature activation (degradation) in the gastric lumen. ${ }^{1}$ Once they reach the duodenum where the $\mathrm{pH}$ is 5.6 or greater, the enteric coating dissolves and unprotonated prodrug is absorbed. The unprotonated compound readily penetrates cell membranes, including that of the parietal cell. It becomes protonated as it transverses the parietal cell and is exposed to the acidic environment in the secretory canaliculus.

Transition from an uncharged to a charged molecule alters membrane permeability of the PPI, converting it from a species that can freely permeate lipid membranes to one that cannot. The drug becomes trapped in the parietal cell when it is protonated. ${ }^{13}$ In addition to confining the PPI to a therapeutically relevant location, protonation of the prodrug begins a series of 
chemical rearrangements that culminates in formation of a sulfenamide moiety, which is the active inhibitory species (Figure 2). ${ }^{13,14}$

The $\mathrm{pK}_{\mathrm{a}}$ of the agent (Table 1),1,13,15-18 in concert with environmental $\mathrm{pH}$, influences the degree of accumulation in the parietal cell, rate of activation, and acid stability. ${ }^{12-14,19}$ Although differences in activation rate among the agents can be seen in vitro at high $\mathrm{pH}$ values, such as 5.1 , the secretory canaliculus of the active parietal cell is the most acidic region in the body $(\mathrm{pH}<1) .{ }^{13,19}$ At low $\mathrm{pH}$, such as would be seen in the secretory canaliculus of the parietal cell, all PPIs are rapidly converted to the cyclic sulfenamide active moiety. ${ }^{19}$ A PPI with a higher $\mathrm{pK}_{\mathrm{a}}$ theoretically may be activated in mildly acidic environments outside the stomach, such as in lysosomes and macrophages. However, clinical data supporting this theory are lacking. Some claim that pantoprazole with a lower $\mathrm{pK}_{\mathrm{a}}$ is more specific for targeted activation in the parietal cell and thus may have a better safety profile than other PPIs. ${ }^{15,19}$ However, to date, no major differences in safety profiles have been observed in clinical trials.

Once formed, the active sulfenamide moiety covalently binds with selected cysteine residues of $\mathrm{H}^{+}, \mathrm{K}^{+}$-ATPase. In studies with radiolabeled PPI preparations, all PPIs bound to a distinct cysteine (residue 813) contained in a loop of $\mathrm{H}^{+}, \mathrm{K}^{+}$-ATPase that connects two membranespanning segments of the enzyme. ${ }^{15,20,21}$ Binding to cysteine residue 813 leads to inhibition of acid secretion. ${ }^{20}$ The drugs bind other cysteine residues as well, and in this respect they vary in their selectivity. In addition to cysteine 813, pantoprazole binds to cysteine 822 , located deeper in the membrane domain of the $\mathrm{H}^{+}, \mathrm{K}^{+}-$ ATPase enzyme. ${ }^{20,21}$ Omeprazole, lansoprazole, and rabeprazole bind to cysteine 892. Lansoprazole and rabeprazole bind to cysteine 321 as well. ${ }^{20}$

Differences in cysteine binding are thought to lead to potential differences in duration of action among PPIs. Originally, it was assumed that restoration of pump activity after administration of a PPI was strictly dependent on synthesis of new enzyme because binding of the drug to the enzyme is covalent. If this were true, under conditions of equivalent suppression, the kinetics of recovery after cessation of therapy should be roughly the same for all PPIs, with a half-life of approximately 48 hours, which is the pumpprotein half-life in humans. ${ }^{21,22}$ What occurs, in fact, is that half-lives of recovery differ among the agents. ${ }^{21,23}$

In a pharmacokinetic-pharmacodynamic model based on data from human subjects, recovery from lansoprazole and omeprazole inhibition was faster than anticipated, with half-lives of turnover of approximately 13 and 27 hours, respectively. ${ }^{23}$ The duration of action for pantoprazole was much longer, with a half-life of turnover of approximately 46 hours, close to that expected if de novo synthesis of proton pumps were the sole mechanism of restoring activity. This behavior is consistent with in vitro experiments in which the naturally occurring intracellular sulfhydrylreducing agent glutathione rapidly and completely restored $\mathrm{H}^{+}, \mathrm{K}^{+}$-ATPase activity after in vivo inhibition by omeprazole, esomeprazole,
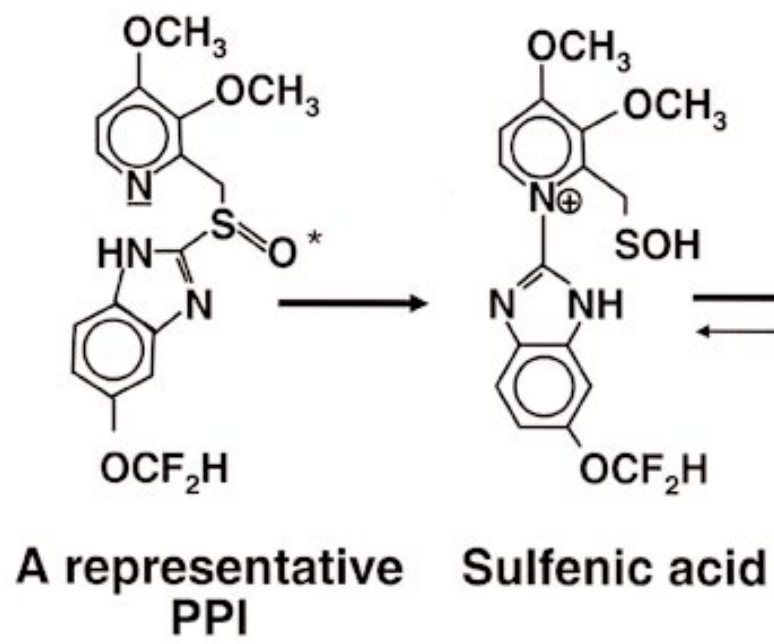
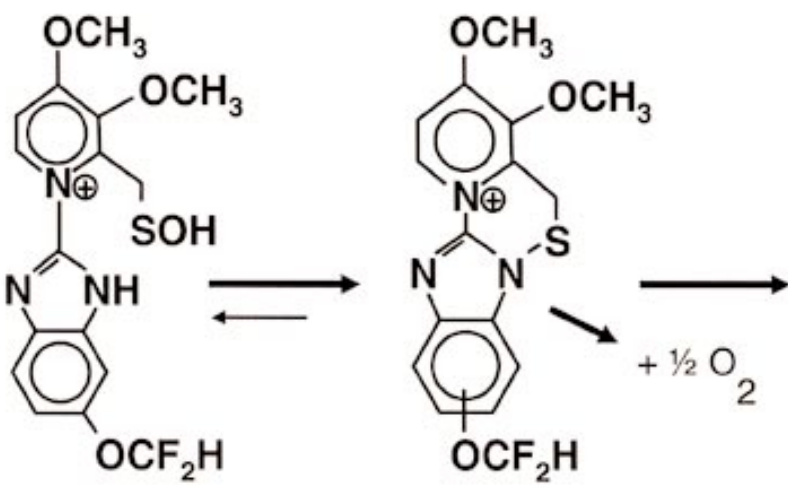

Sulfenamide

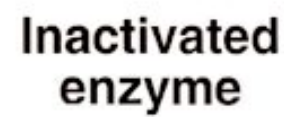

Figure 2. Activation pathway for proton pump inhibitors. *Pantoprazole. (From reference 14.) 
lansoprazole, or rabeprazole. ${ }^{21}$ In contrast, glutathione only partially restored activity to pantoprazole-inhibited $\mathrm{H}^{+}, \mathrm{K}^{+}$-ATPase. The investigators concluded that pantoprazole's binding to cysteine 822 confers resistance to the accelerated reversal of binding seen with the other PPIs and suggests that pantoprazole has a longer duration of action.

\section{Pharmacokinetics}

The oral drugs are formulated as enteric-coated delayed-release prodrugs that are extensively absorbed in the small bowel. ${ }^{1,}$ Although oral products undergo first-pass metabolism to inactive products, they have relatively high bioavailability.16, 24 In contrast, when pantoprazole is administered intravenously, it bypasses hepatic first-pass metabolism. ${ }^{24}$ The bioavailability of omeprazole and esomeprazole after oral administration increases over the first 5 days of therapy. ${ }^{25-28}$ These increases in area under the concentration-time curve (AUC) and bioavailability result from a decrease in first-pass extraction, which likely is due to a decrease in acid degradation in the gastric lumen as gastric $\mathrm{pH}$ rises over the first few days of therapy, and inhibition of the drug's own metabolism. ${ }^{26-28}$ With omeprazole, the most acid-labile PPI, the gradual decrease in amount of gastric acid delivered into the duodenum as the agent takes effect may protect more of it from degradation. ${ }^{26,27}$

Others suggested that increases in AUC and bioavailability with omeprazole and esomeprazole result from autoinhibition of metabolism. ${ }^{26,28}$ Support for this theory comes from data showing a decrease in systemic clearance of esomeprazole after intravenous dosing. ${ }^{28}$ Thus, these increases during the first few days of omeprazole and esomeprazole therapy are most likely multifactorial. ${ }^{25}, 28$ The oral bioavailabilities of lansoprazole, pantoprazole, and rabeprazole are consistent over time, and substantial increases over the first few days of therapy do not occur. ${ }^{29-32}$

The PPIs have relatively short elimination halflives; however, this has minimal bearing on their pharmacodynamic properties in that covalent binding to the $\mathrm{H}^{+}, \mathrm{K}^{+}$-ATPase enzyme predominately influences the duration of antisecretory action. ${ }^{1}$ Specifically, covalent binding to the cysteine residues of the proton pump leads to a duration of action that is substantially longer than would be predicted based strictly on the plasma concentration profile. ${ }^{21,23}$
All PPIs undergo extensive metabolism, with metabolites eliminated in urine and feces., 25, 32 They are all metabolized in part by cytochrome P450 (CYP) 2C19 and 3A, but to various degrees. Omeprazole is predominately metabolized by CYP2C19, with dose-dependent saturation of the isoenzyme. $^{32}$ Pantoprazole is metabolized by both 2C19 and 3A and is metabolized by sulfotransferase, a non-CYP isoenzyme. ${ }^{3,32}$ Rabeprazole is not only metabolized by 2C19 and $3 \mathrm{~A}$, but it also undergoes nonenzymatic reduction to a thioether metabolite. ${ }^{1,33}$

The CYP2C19 isoenzyme, which sometimes is referred to as S-mephenytoin $4^{\prime}$ hydroxylase, displays genetically determined polymorphism. ${ }^{34,35}$ The 2C19 gene is located on chromosome 10, and at least two different mutations have been associated with poor metabolizer phenotype: a single base-pair mutation (guanine to adenine) in exon $5\left(\mathrm{CYP} 2 \mathrm{C} 19_{\mathrm{m} 1}\right)$ and in exon $4\left(\mathrm{CYP} 2 \mathrm{C} 19_{\mathrm{m} 2}\right){ }^{35}$, 36 Individuals without the mutant gene are considered extensive metabolizers of PPIs (as well as other 2C19 substrates), whereas those with the mutation are considered poor metabolizers. Mutant alleles are particularly prevalent in Asian populations, affecting $12.6-23 \%$ of Japanese and Korean populations compared with 2.5-6\% of European and North American Caucasian populations. ${ }^{34,36}$ Although all PPIs are metabolized to some degree by 2C19 and are likely affected by metabolizer status, some suggested that the metabolism of rabeprazole is least affected by 2C19 phenotype in that the drug is also metabolized nonenzymatically to a thioether. ${ }^{34,35}$

Slow metabolizers have higher plasma concentrations and longer elimination half-lives than fast metabolizers. Moreover, response to PPIs, as measured by intragastric $\mathrm{pH}$ or cure rates for Heliobacter pylori infection, was higher in poor 2C19 metabolizers compared with extensive metabolizers. ${ }^{36,37}$ The greater response rate is most likely the result of higher plasma concentrations and higher AUC in poor metabolizers, thus allowing for greater exposure of parietal cells to the agent. ${ }^{36}$

The PPIs also have stereoselective metabolism. This is best illustrated by comparing omeprazole and esomeprazole. When omeprazole is given as a racemic mixture, the R-enantiomer is rapidly cleared by the liver, whereas clearance of the Senantiomer is much slower. When esomeprazole is given, one is giving only the S-enantiomer of omeprazole and thus it has slower clearance as compared with the racemic mixture. In extensive 
metabolizers, the AUC for esomeprazole was $60 \%$ higher than that of omeprazole. ${ }^{25}$ In contrast, in poor 2C19 metabolizers, plasma concentrations of esomeprazole were approximately $20 \%$ lower than those of omeprazole. Overall, compared with omeprazole, plasma concentrations of esomeprazole differ less between extensive and poor 2C19 metabolizers.

\section{Pharmacodynamics}

When PPI therapy is begun, the degree of acid suppression increases over the first 3 days until a new steady state for acid secretion is achieved. ${ }^{7}$ This reflects the changes in the number of active pumps available for inhibition each day. The PPIs inhibit only active proton pumps, and before administration on day 1, approximately $80 \%$ of pumps are active after a stimulus such as food and are available for inhibition by the first dose. Before administration of the PPI on day 2, newly synthesized pumps and the remaining 20\% of pumps that were not inhibited the first day are available to be inhibited. Again, approximately $80 \%$ of these pumps are activated and available for inhibition. This process, in which inhibition by the PPI and regeneration of new pumps counteract one another, is repeated until pharmacodynamic steady state is reached in which the number of pumps inhibited each day equals the number of new pumps generated each day. The overall decrease in number of active pumps results in acid suppression, reflected in an increase in the percentage of the day during which gastric $\mathrm{pH}$ is maintained above $4 .^{7}$ Therefore, it takes several days for maximum acid suppression to be achieved. If necessary, administration twice/day (before breakfast and before the evening meal) can reduce the time required to achieve sufficient acid suppression. ${ }^{38}$ However, unlike with $\mathrm{H}_{2} \mathrm{RAs}$, maximum relief is not achieved with the first dose and PPIs are generally not recommended for immediate symptom relief. For example, gastric $\mathrm{pH}$ above 4 could be achieved within 6 hours of administration of ranitidine but not omeprazole. ${ }^{39}$

The timing of PPI dosing is critical to achieving maximum acid suppression and therapeutic benefit. Dosing should be 30-60 minutes before breakfast (or the first substantial meal of the day), as the greatest number of pumps is activated with a meal that follows a prolonged fast. This allows the drug to be absorbed and to reach parietal cells when the greatest number of pumps is likely to be activated and available for inhibition..$^{38,40}$ The advantage of administration before breakfast instead of an evening meal is clear, as median $\mathrm{pH}$ is 5.0 after a morning dose of omeprazole, compared with 4.5 after an evening dose $(\mathrm{p}<0.01) .{ }^{40}$ If greater acid suppression is required, an additional dose should be given before dinner. ${ }^{1}$

Food can influence absorption of some PPIs. Specifically, maximum concentration and AUC of lansoprazole and esomeprazole are diminished when they are taken with food. ${ }^{11,41}$ In contrast, the bioavailabilities of pantoprazole, omeprazole, and rabeprazole are unaffected by food. ${ }^{33,42,43}$

The degree of acid inhibition for a given PPI is related to the AUC. ${ }^{37}$ The AUC is an indirect measure or surrogate for exposure of parietal cells to the PPI over time. The longer the plasma concentration remains above the threshold concentration necessary to inhibit the proton pumps, the greater the number of pumps that can be inhibited as they become activated during the day. $^{7,44}$ For a given agent, the higher the AUC, the greater the degree of inhibition of acid secretion. ${ }^{7,36}$ This relationship also provides an explanation as to why poor CYP2C19 metabolizers have a better response to most PPIs than extensive metabolizers. ${ }^{36,37}$

Conceptually, inhibition of acid secretion by PPIs is influenced by the dwell time of the drug in parietal cells. Exposure of the proton pump to a PPI over time is influenced by the AUC. ${ }^{37}$ Thus, the longer plasma concentrations remain above the threshold required to inhibit the pump, the greater the number of proton pumps that will be inactivated over time with subsequent meals. The duration of action of a PPI is then influenced by binding to cysteine residues of active proton pumps. ${ }^{21}$

Unlike $\mathrm{H}_{2} \mathrm{RAs}$, tolerance does not develop during PPI therapy. ${ }^{45}$ Once effective acid suppression has been achieved with a PPI, it can be maintained over the long term without increasing the dosage. In contrast, tolerance to $\mathrm{H}_{2}$ RAs develops rapidly within 3-5 days of therapy. ${ }^{45-47}$ For example, loss of pharmacodynamic effect (tolerance) was seen within 48-72 hours during continuous infusions of ranitidine but not with continuous infusions of omeprazole. ${ }^{45}$

After cessation of PPI therapy, as with $\mathrm{H}_{2} \mathrm{RA}$ therapy, rebound acid hypersecretion may occur. ${ }^{48}$ This probably reflects increases in gastrin secretion during acid suppression, which in turn stimulates growth of ECL cells responsible for histamine release. The increase in ECL cell number increases the capacity for 
gastric acid secretion, which results in acid hypersecretion. In rats, acid hypersecretion persisted for at least 70 days, ${ }^{49}$ but it is unclear whether it is likely to last as long in humans.

\section{Potential for Drug Interactions}

Since $\mathrm{H}_{2} \mathrm{RAs}$ and PPIs increase gastric $\mathrm{pH}$, they can alter the absorption of drugs that are weak acids or bases, are prone to acid or alkaline degradation, or are formulated in a $\mathrm{pH}$ dependent controlled-release dosage form. ${ }^{1,50}$ A high gastric $\mathrm{pH}$ increases absorption of digoxin, nifedipine, aspirin, midazolam, didanosine, and methadone, but the clinical significance of these effects is unclear. ${ }^{50}$ More important, absorption of weak bases such as ketoconazole, cefpodoxime proxetil, itraconazole, and enoxacin is decreased when gastric $\mathrm{pH}$ is increased, which can reduce clinical efficacy. These types of interactions are difficult to minimize because they reflect the pharmacologic effects of acid suppressors.

Although all PPIs are metabolized to some degree by CYP2C19 and 3A, their propensity to interact with the CYP system varies. Omeprazole and esomeprazole inhibit 2C19 and interact with diazepam, phenytoin, and the R-isomer of warfarin. ${ }^{1,50,51}$ Lansoprazole induced metabolism of CYP1A2 and led to a slight increase in metabolism of theophylline. ${ }^{1}$ Rabeprazole and pantoprazole do not interact with the CYP system. ${ }^{1}$

\section{Summary}

The PPIs are an important advance in the management of acid-related disorders. With the introduction of esomeprazole, five drugs are now available. They share a common core structure, a similar mechanism of action, and many clinical characteristics. They are highly potent suppressors of gastric acid secretion and are agents of choice for the treatment of many acid-related disorders. Differences in their chemical structure result in subtle pharmacokinetic differences that theoretically may translate into differences in efficacy and safety profile. The availability of an intravenous PPI extends the use of these agents to the hospital setting.

\section{References}

1. Welage LS, Berardi RR. Evaluation of omeprazole, lansoprazole, pantoprazole, and rabeprazole in the treatment of acid-related diseases. J Am Pharm Assoc (Wash) 2000; 40:52-62.

2. Anonymous. Pantoprazole IV (Protonix IV). Med Lett Drugs Ther 2002;44:41-2.
3. Wyeth Laboratories. Protonix IV (pantoprazole IV) package insert. Philadelphia, PA; 2002.

4. Pisegna JR. Switching between intravenous and oral pantoprazole. J Clin Gastroenterol 2001;32:27-32.

5. Metz DC. Potential uses of intravenous proton pump inhibitors to control gastric acid secretion. Digestion 2000;62:73-81.

6. Feldman M. Gastric secretion: normal and abnormal. In: Feldman M, Scharschmidt BF, Sleisenger MH, eds. Gastrointestinal and liver disease. Philadelphia: WB Saunders, 1998:587-603.

7. Modlin IM, Sachs G, eds. Gastric acid secretion. In: Acid related diseases: biology and treatment. Konstanz, Germany: Schnetztor-Verlag GmbH D-Konstanz, 1998:61-91.

8. Olbe L, ed. Proton pump inhibitors. Basel: Birkhauser Verlag, 1999.

9. Metz DC, Ferron GM, Paul J, et al. Proton pump activation in stimulated parietal cells is regulated by gastric acid secretory capacity: a human study. J Clin Pharmacol 2002;42:512-19.

10. Hasselgren G, Hassan-Alin M, Andersson T, Claar-Nilsson C, Rohss K. Pharmacokinetic study of esomeprazole in the elderly. Clin Pharmacokinet 2001;40:145-50

11. AstraZeneca. Nexium (esomeprazole) package insert. Wilmington, DE; 2000.

12. Kromer W. Relative efficacies of gastric proton-pump inhibitors on a milligram basis: desired and undesired $\mathrm{SH}$ reactions. Impact of chirality. Scand J Gastroenterol 2001;36(suppl 234):3-9.

13. Petersen KU. Comparison of different proton pump inhibitors. In: Olbe L, ed. Proton pump inhibitors. Basel: Birkhauser Verlag, 1999:143-57.

14. Kromer W. Similarities and differences in the properties of substituted benzimidazoles: a comparison between pantoprazole and related compounds. Digestion 1995;56:443-54.

15. Andersson T, Holmberg J, Rohss K, Walan A. Pharmacokinetics and effect on caffeine metabolism of the proton pump inhibitors, omeprazole, lansoprazole, and pantoprazole. Br J Clin Pharmacol 1998;45:369-75.

16. Welage LS, Karlstadt RG, Burton MS, Lynn RB. Pharmacokinetic comparison of five proton pump inhibitors. Presented at Digestive Disease Week, San Francisco, May 19-22, 2002.

17. Spencer CM, Fauds D. Esomeprazole. Drugs 2000;60:321-9.

18. Benet LZ, Zech K. Pharmacokinetics-a relevant factor for the choice of a drug? Aliment Pharmacol Ther 1994;8(suppl 1):25-32.

19. Kromer W, Kruger U, Huber R, Hartmann M, Steinijans VW. Differences in $\mathrm{pH}$-dependent activation rates of substituted benzimidazoles and biological in vitro correlates. Pharmacology 1998;56:57-70.

20. Besancon M, Simon A, Sachs G, Shin JM. Sites of reaction of the gastric H,K-ATPase with extracytoplasmic thiol reagents. J Biol Chem 1997;272:22438-46.

21. Shin JM, Sachs G. Restoration of acid secretion following treatment with proton pump inhibitors. Gastroenterology 2002;123:1588-97.

22. Gedda K, Scott D, Besancon M, Lorentzon P, Sachs G. Turnover of the gastric $\mathrm{H}^{+}, \mathrm{K}^{+}$-adenosine triphosphatase a subunit and its effect on inhibition of rat gastric acid secretion. Gastroenterology 1995;109:1134-41.

23. Katashima M, Yamamoto K, Tokuma Y, et al. Comparative pharmacokinetic/pharmacodynamic analysis of proton pump inhibitors omeprazole, lansoprazole and pantoprazole, in humans. Eur J Drug Metab Pharmacokinet 1998;23:19-26.

24. Pue MA, Laroche J, Meineke I, de Mey C. Pharmacokinetics of pantoprazole following single intravenous and oral administration to healthy male subjects. Eur J Clin Pharmacol 1993;44:575-8.

25. Andersson T, Hassan-Alin M, Hasselgren G, Rohss K, Weidolf L. Pharmacokinetic studies with esomeprazole, the (S)-isomer of omeprazole. Clin Pharmacokinet 2001;40:411-26.

26. Andersson T, Andren K, Cederberg C, Lagerstrom PO, Lundborg P, Skanberg I. Pharmacokinetics and bioavailability of omeprazole after single and repeated oral administration in healthy subjects. Br J Clin Pharmacol 1990;29:557-63. 
27. Ching MS, Mihaly GW, Angus PW, et al. Oral bioavailability of omeprazole before and after chronic therapy in patients with duodenal ulcer. Br J Clin Pharmacol 1991;31:166-70.

28. Hassan-Alin M, Andersson T, Bredberg E, Rohss K Pharmacokinetics of esomeprazole after oral and intravenous administration of single and repeated doses to healthy subjects. Eur J Clin Pharmacol 2000;56:665-70.

29. Simon B, Muller P, Marinis E, et al. Effect of repeated oral administration of BY 1023/SK\&F 96022-a new substituted benzimidazole derivative-on pentagastrin-stimulated gastric acid secretion and pharmacokinetics in man. Aliment Pharmacol Ther 1990;4:373-9.

30. Landes BD, Petite JP, Flouvat B. Clinical pharmacokinetics of lansoprazole. Clin Pharmacokinet 1995;28:458-70.

31. Yasuda S, Ohnishi A, Ogawa T, et al. Pharmacokinetic properties of E3810, a new proton pump inhibitor, in healthy male volunteers. Int J Clin Pharmacol Ther 1994;32: 466-73.

32. Stedman CA, Barclay ML. Comparison of the pharmacokinetics, acid suppression and efficacy of proton pump inhibitors. Aliment Pharmacol Ther 2000;14:963-78.

33. Eisai Co. Aciphex (rabeprazole sodium) delayed-release tablets. Teaneck, NJ; 2001

34. Ishizaki T, Chiba K, Manabe K, et al. Comparison of the interaction potential of a new proton pump inhibitor, E3810, versus omeprazole with diazepam in extensive and poor metabolizers of S-mephenytoin 4'-hydroxylation. Clin Pharmacol Ther 1995;58:155-64.

35. Sakai T, Aoyama N, Kita T, et al. CYP2C19 genotype and pharmacokinetics of three proton pump inhibitors in healthy subjects. Pharm Res 2001;18:721-7.

36. Furuta T, Ohashi K, Kosuge K, et al. CYP2C19 genotype status and effect of omeprazole on intragastric $\mathrm{pH}$ in humans. Clin Pharmacol Ther 1999;65:552-61.

37. Furuta T, Ohashi K, Kamata T, et al. Effect of genetic differences in omeprazole metabolism on cure rates for Helicobacter pylori infection and peptic ulcer. Ann Intern Med 1998;129:1027-30.

38. Wolfe MM, Sachs G. Acid suppression: optimizing therapy for gastroduodenal ulcer healing, gastroesophageal reflux disease, and stress-related erosive syndrome. Gastroenterology
2000;118:S9-31.

39. Khoury RM, Katz PO, Castell DO. Post-prandial ranitidine is superior to post-prandial omeprazole in control of gastric acidity in healthy volunteers. Aliment Pharmacol Ther 1999;13:1211-14.

40. Prichard PJ, Yeomans ND, Mihaly GW, et al. Omeprazole: a study of its inhibition of gastric $\mathrm{pH}$ and oral pharmacokinetics after morning or evening dosage. Gastroenterology 1985; 88:64-9.

41. TAP Pharmaceuticals. Prevacid (lansoprazole) package insert. Lake Forest, IL; 2002

42. Wyeth Laboratories. Protonix (pantoprazole) delayed-release tablets package insert. Philadelphia, PA; 2001.

43. AstraZeneca. Prilosec (omeprazole) package insert Wilmington, DE; 2000

44. Junghard O, Hassan-Alin M, Hasselgren G. The effect of the area under the plasma concentration vs time curve and the maximum plasma concentration of esomeprazole on intragastric pH. Eur J Clin Pharmacol 2002;58:453-8.

45. Merki HS, Wilder-Smith CH. Do continuous infusions of omeprazole and ranitidine retain their effect with prolonged dosing? Gastroenterology 1994;106:60-4.

46. Gillen D, McColl KE. Problems related to acid rebound and tachyphylaxis. Baillieres Best Pract Res Clin Gastroenterol 2001;15:487-95.

47. Huang JQ, Hunt RH. Pharmacological and pharmacodynamic essentials of $\mathrm{H}(2)$-receptor antagonists and proton pump inhibitors for the practising physician. Baillieres Best Pract Res Clin Gastroenterol 2001;15:355-70.

48. Waldum HL, Arnestad JS, Brenna E, Eide I, Syversen U, Sandvik AK. Marked increase in gastric acid secretory capacity after omeprazole treatment. Gut 1996;39:649-53.

49. Larsson H, Carlsson E, Ryberg B, Fryklund J, Wallmark B. Rat parietal cell function after prolonged inhibition of gastric acid secretion. Am J Physiol 1988;254:G33-9.

50. Welage LS, Berardi RR. Drug interactions with antiulcer agents: considerations in the treatment of acid-peptic disease. J Pharm Pract 1994:6:177-95.

51. Andersson T, Hassan-Alin M, Hasselgren G, Rohss K. Drug interaction studies with esomeprazole, the (S)-isomer of omeprazole. Clin Pharmacokinet 2001;40:523-37. 